\title{
Racemic Descriptors for Quantitative Structure Activity Relationship of Spirosuccinimide Type Aldose Reductase Inhibitors
}

\author{
Jeong Rim Kim ${ }^{\star}$ and Youngdo Won ${ }^{\dagger}$ \\ Deparment of Applied Chemistry and Chemistry, Hanvang Chiversity Ansan 425-791. Korea \\ ${ }^{\dagger}$ Department of Chemistry, Hanvang Lniversity, Seoul 133-792, Korea \\ Received September 22, 2004
}

\begin{abstract}
Quantitative structure activity relationship has been probed for spirosuccinimide-fused tetrahydropy rrolo[1,2$a$ ]pyrazine-1,3-dione derivatives acting as aldose reductase inlibitors. While the spirosuccinimide contpounds contain a chiral center, the aldose reductase inhibition assay was performed with racenic nuixtures in the published work. As the physicochemical descriptors of the QSAR analysis must be evaluated for a definite molecular structure, we devise a new "racemic" descriptor as the aritlunetic mean of the $(R)$-enantioner descriptor and the (S)-enantiomer descriptor. The resultant QSAR model derived from the racemic descriptors outperforms the original QSAR models, closely reproducing the observed activity of optically pure enantiomers as well as racemic mixtures.
\end{abstract}

Key Words : QSAR, Racemic descriptor, Aldose reductase inlibitor

Modem drug discovery research relies on massive synthesis. assay and rational design of compounds to generate de novo lead molecular constructs. ${ }^{1.2}$ The lead compound is further optimized to enhance potency and deliverability: Quantitative structure activity relationship (QSAR) investigation aids lead optimization by analyzing the assay data in terms of molecular descriptors. While drug candidate molecules often contain chiral centers. the activity assay is rarely performed with optically pure enantiomers. In such cases. it is a challenging question which molecular structure to employ in evaluating the QSAR descriptors. We consider a simple arithmetic mean of enantiomeric descriptors as the QSAR basis and demonstrate its applicability to the QSAR analysis of spirosuccinimide aldose reductase inhibitors.

Aldose reductase (AR) is the first enzyme of the sorbitol pathway in which it converts glucose to sorbitol. ${ }^{3}$ As high intracellular sorbitol accumulation causes chronic diabetic complications such as retinopathy. neuropathy. nephropathy. and cataracts. ${ }^{+}$inluibition of AR is an effective treatment for long-term diabetic malignity: "Negoro et al. șynthesized tetrahydropyrrolo[ $1,2-\alpha]$ py razine derivatives and performed the assay. ${ }^{\circ}$ Although the spirosuccinimide cogeners contain the chiral center indicated by ${ }^{*}$ in the figure of Table 1 , the $A R$ inhibition assay is performed with racemic mixtures.

We obtain $\mathrm{IC}_{\text {si }}$ values of 30 spirosuccinimide compounds from the published data of Negoro et $a l$. The AR inhibitory activity is defined as $\mathrm{pIC}_{5 i}=-\log \left(\mathrm{IC}_{\underline{S}}\right)$. The normalized $\mathrm{plC}_{5 i}$ values of the training set are listed in Table 1 . We utilize the Cerius ${ }^{2}$ program package ${ }^{7}$ and separately build the (S)-enantiomer and $(R)$-enantiomer molecular structures of the pyrrolo[1.2- $\alpha]$ pyrazine-4-spiro-3'-pyrrolidine-1.2'.3.5'tetrone derivatives. For each enantiomer. thorough conformational search and energy minimization result in the

\footnotetext{
"Corresponding Author. Tel: $-82-31-400-5491$ : Fax: $-82-31-407$.
} 3863: e-mail: jrkim ghanyang.ac. $\mathrm{kr}$ optimized molecular geometry. The adopted basis Newton Raphson minimization method is used with the Merck Molecular Force Field. The optimized geometry is aligned to that of the most potent compound. 2-(4-bromo-2-fluorobenzyl)-1,2,3.4-tetrahyddropyrrolo[1.2- $\alpha$ ]pyrazine-4-spiro-3'pyrrolidine-1.2'.3.5'-tetrone (SX-3030). We used atomic charges assigned by the charge equilibration method for descriptor evaluation.

The QSAR ${ }^{-}$module of the Cerius' package generates 78 physicochemical descriptors for each enantiomer. $R$-descriptors. as we define. are based on the optimized structure of the $(R)$-enantiomers and $S$-descriptors are derived for the $(S)$-enantiomers. We take the respective arithmetic mean values of $R$-descriptors and $S$-descriptors to generate the new set of descriptors. RS-descriptors. In order to warrant evenly distributed descriptor basis. descriptors with the standard deviation smaller than that of the $\mathrm{pIC}_{5 i}$ values are removed to leave 48 descriptors in each set.

The genetic function approximation method is applied to the over-determined QSAR problem of 48 descriptors for 30 compounds. ${ }^{9}$ The random selection of both linear and quadratic descriptors generates the initial models. which evolve through genetic crossover operations. 20.000 genetic operations are performed to derive the best QSAR equation.

We drive three sets of QSAR equations: $R$-equations with $R$-descriptors. $S$-equations with $S$-descriptors, and $R S$ equations with $R S$-descriptors. As detailed QSAR analyses will appear somewhere else here we concentrate on the performance comparison among the descriptor sets. The genetic function algorithm is applied to each descriptor set with successively increasing the number of terms in the QSAR equation. This procedure determines the necessary and sufficient QSAR equation with parsimony of terms. The statistics of the best QSAR equations with one through eight terms is summarized in Table 2.

The QSAR equations fit the training data set more closely 
Table 1. Predicted and observed aldose reductase inhibitory activity data of $2,6,7-$ Substituted- $1,2,3,4$-tetrahydropyrrolo[ $1,2-a]$ pyrazine-4spiro- $\hat{3}^{\prime}$-pyrrolidine- $1,2^{1}, \hat{3}, 3^{\prime}$-tetrones $\mathrm{s}^{\text {ar. }}$

\begin{tabular}{|c|c|c|c|c|c|c|c|c|}
\hline \multirow{2}{*}{ Compd } & \multirow{2}{*}{$\mathrm{R}_{1}$} & \multirow{2}{*}{$\mathrm{R}_{2}$} & \multirow{2}{*}{$\mathrm{R}_{3}$} & \multirow{2}{*}{$\mathrm{R}_{4}$} & \multicolumn{4}{|c|}{$\mathrm{pIC}_{\zeta(1} \mathrm{c}^{\mathrm{c}}$} \\
\hline & & & & & observed & $R$-eqn & $S$-eqn & $R S$-eqn \\
\hline 1 & - & $\mathrm{H}$ & $\mathrm{H}$ & $\mathrm{H}$ & 0.201 & 0.430 & 0.343 & 0.330 \\
\hline 2 & - & $\mathrm{H}$ & $\mathrm{H}$ & $\mathrm{CH}_{3-}$ & 0.553 & 0.489 & 0.426 & 0.365 \\
\hline 3 & - & $\mathrm{H}$ & $\mathrm{H}$ & $\mathrm{C}_{k} \mathrm{H}_{\xi-}$ & 0.699 & 0.581 & 0.531 & 0.611 \\
\hline 4 & - & $\mathrm{H}$ & $\mathrm{H}$ & $\mathrm{C}_{6} \mathrm{H}_{\xi}-\left(\mathrm{CH}_{2}\right)_{2-}$ & 0.569 & 0.591 & 0.801 & 0.584 \\
\hline 5 & $\mathrm{H}$ & $\mathrm{H}$ & $\mathrm{H}$ & $\mathrm{C}_{6} \mathrm{H}_{4}-\mathrm{CH}_{2-}$ & 1.004 & 1.018 & 1.267 & 1.203 \\
\hline 6 & $2-F$ & $\mathrm{H}$ & $\mathrm{H}$ & $\mathrm{C}_{6} \mathrm{H}_{4}-\mathrm{CH}_{-}-$ & 1.215 & 1.230 & 1.170 & 1.259 \\
\hline 7 & $4-F$ & $\mathrm{H}$ & $\mathrm{H}$ & $\mathrm{C}_{6} \mathrm{H}_{4}-\mathrm{CH}_{-}$ & 0.921 & 1.050 & 1.090 & 1.209 \\
\hline 8 & $2-\mathrm{Cl}$ & $\mathrm{H}$ & $\mathrm{H}$ & $\mathrm{C}_{6} \mathrm{H}_{4}-\mathrm{CH}_{2-}$ & 1.432 & 1.140 & 1.348 & 1.188 \\
\hline 9 & $3-\mathrm{Cl}$ & $\mathrm{H}$ & $\mathrm{H}$ & $\mathrm{C}_{6} \mathrm{H}_{4}-\mathrm{CH}_{2-}$ & 1.456 & 1.472 & 1.481 & 1.519 \\
\hline 10 & $4-\mathrm{Cl}$ & $\mathrm{H}$ & $\mathrm{H}$ & $\mathrm{C}_{6} \mathrm{H}_{4}-\mathrm{CH}_{2-}$ & 1.420 & 1.216 & 1.373 & 1.308 \\
\hline 11 & $2-\mathrm{Br}$ & $\mathrm{H}$ & $\mathrm{H}$ & $\mathrm{C}_{5} \mathrm{H}_{4}-\mathrm{CH}_{2-}$ & 1.284 & 1.134 & 1.184 & 1.193 \\
\hline 12 & $3-\mathrm{Br}$ & $\mathrm{H}$ & $\mathrm{H}$ & $\mathrm{C}_{6} \mathrm{H}_{4}-\mathrm{CH}_{2-}$ & 1.432 & 1.540 & 1.345 & 1.475 \\
\hline 13 & $4-\mathrm{Br}$ & $\mathrm{H}$ & $\mathrm{H}$ & $\mathrm{C}_{6} \mathrm{H}_{4}-\mathrm{CH}_{2-}^{-}$ & 1.328 & 1.319 & 1.245 & 1.376 \\
\hline 14 & $4-\mathrm{CH}_{3}$ & $\mathrm{H}$ & $\mathrm{H}$ & $\mathrm{C}_{6} \mathrm{H}_{4}-\mathrm{CH}_{-}^{-}$ & 1.284 & 1.278 & 1.317 & 1.149 \\
\hline 15 & $4-\mathrm{OCH}_{3}$ & $\mathrm{H}$ & $\mathrm{H}$ & $\mathrm{C}_{6} \mathrm{H}_{4}-\mathrm{CH}_{2}-$ & 1.337 & 1.248 & 1.107 & 1.159 \\
\hline 16 & $4-\mathrm{CF}_{3}$ & $\mathrm{H}$ & $\mathrm{H}$ & $\mathrm{C}_{6} \mathrm{H}_{4}-\mathrm{CH}_{-}-$ & 1.097 & 0.996 & 1.104 & 1.116 \\
\hline 17 & $4-\mathrm{NO}_{2}$ & $\mathrm{H}$ & $\mathrm{H}$ & $\mathrm{C}_{6} \mathrm{H}_{4}-\mathrm{CH}_{-}$ & 0.959 & 0.897 & 1.143 & 0.994 \\
\hline 18 & $4-\mathrm{NH}_{2}$ & $\mathrm{H}$ & $\mathrm{H}$ & $\mathrm{C}_{6} \mathrm{H}_{4}-\mathrm{CH}_{-}-$ & 0.854 & 0.790 & 0.961 & 0.786 \\
\hline 19 & $2,4-\left(\mathrm{OCH}_{3}\right)_{2}$ & $\mathrm{H}$ & $\mathrm{H}$ & $\mathrm{C}_{6} \mathrm{H}_{3}-\mathrm{CH}_{-}-$ & 0.456 & 0.492 & 0.492 & 0.578 \\
\hline 20 & $3,4-\left(\mathrm{OCH}_{3}\right)_{2}$ & $\mathrm{H}$ & $\mathrm{H}$ & $\mathrm{C}_{6} \mathrm{H}_{3}-\mathrm{CH}_{-}$ & 0.959 & 0.915 & 0.900 & 1.000 \\
\hline 21 & $2,4-F_{2}$ & $\mathrm{H}$ & $\mathrm{H}$ & $\mathrm{C}_{6} \mathrm{H}_{2}-\mathrm{CH}_{2}-$ & 1.143 & 1.252 & 1.032 & 1.253 \\
\hline 22 & $3,4-\mathrm{Cl}_{2}$ & $\mathrm{H}$ & $\mathrm{H}$ & $\mathrm{C}_{6} \mathrm{H}_{2}-\mathrm{CH}_{2-}$ & 1.638 & 1.538 & 1.689 & 1.559 \\
\hline 23 & $2-\mathrm{F}, 4-\mathrm{Cl}$ & $\mathrm{H}$ & $\mathrm{H}$ & $\mathrm{C}_{6} \mathrm{H}_{2}-\mathrm{CH}_{2-}$ & 1.387 & 1.377 & 1.285 & 1.291 \\
\hline 24 & $2-\mathrm{F}, 4-\mathrm{Br}$ & $\mathrm{H}$ & $\mathrm{H}$ & $\mathrm{C}_{6} \mathrm{H}_{2}-\mathrm{CH}_{2-}$ & 1.347 & 1.491 & 1.189 & 1.337 \\
\hline 25 & $2-\mathrm{F}, 4-\mathrm{Br}$ & $\mathrm{H}$ & $\mathrm{Cl}$ & $\mathrm{C}_{6} \mathrm{H}_{2}-\mathrm{CH}_{2-}$ & 1.301 & 1.262 & 1.355 & 1.168 \\
\hline 26 & $2-\mathrm{F}, 4-\mathrm{Br}$ & $\mathrm{H}$ & $\mathrm{Br}$ & $\mathrm{C}_{6} \mathrm{H}_{2}-\mathrm{CH}_{2-}$ & 1.000 & 1.338 & 1.364 & 1.239 \\
\hline 27 & $2-\mathrm{F}, 4-\mathrm{Br}$ & $\mathrm{H}$ & $\mathrm{CH}_{3} \mathrm{CO}$ & $\mathrm{C}_{6} \mathrm{H}_{3}-\mathrm{CH}_{-}-$ & 0.678 & 1.041 & 0.776 & 0.835 \\
\hline 28 & $2-\mathrm{F}, 4-\mathrm{BT}$ & $\mathrm{Cl}$ & $\mathrm{H}$ & $\mathrm{C}_{6} \mathrm{H}_{3}-\mathrm{CH}_{--}$ & 1.456 & 1.304 & 1.338 & 1.372 \\
\hline 29 & $2-\mathrm{F}, 4-\mathrm{BT}$ & $\mathrm{Br}$ & $\mathrm{H}$ & $\mathrm{C}_{6} \mathrm{H}_{3}-\mathrm{CH}_{-}-$ & 1.398 & 1.317 & 1.170 & 1.458 \\
\hline 30 & $2-\mathrm{F}, 4-\mathrm{Br}$ & $\mathrm{BI}$ & $\mathrm{Br}$ & $\mathrm{C}_{6} \mathrm{H}_{3}-\mathrm{CH}_{-}-$ & 1.284 & 1.342 & 1.264 & 1.174 \\
\hline
\end{tabular}

"The observed $i n$ vitro activity falues are obtained from Negoro ef $a f^{\circ}{ }^{\circ}$ The chiral center is denoted by ${ }^{*} *$. The pyrollo[ $[1.2-\alpha]$ pyrazine ring is placed in the yz-plane and the $\mathrm{CN}$ bond of the tive membered aromatic ring is aligned to the $\mathrm{z}$-axis. " $\mathrm{pIC} \mathrm{C}_{5 n}=-\log \left(\mathrm{IC} \mathrm{C}_{5,}\right)$ is normalized for the QSAR analyses. IC $5 n$ value in $\mu \mathrm{M}$.

Table 2. Statistical Evaluation of QSAR Models"

\begin{tabular}{|c|c|c|c|c|c|c|c|c|c|}
\hline \multirow{2}{*}{$\begin{array}{l}\text { Number } \\
\text { of Tenms }\end{array}$} & \multicolumn{3}{|c|}{$R$-Equations } & \multicolumn{3}{|c|}{$S$-Equations } & \multicolumn{3}{|c|}{ RS-Equations } \\
\hline & $T$ & $s$ & $\mathrm{~F}_{s}$ & $T$ & $\$$ & $\mathrm{~F}_{s}$ & $r$ & $s$ & $F_{s}$ \\
\hline 1 & 0.730 & 0.247 & & 0.730 & 0.247 & & 0.730 & 0.247 & \\
\hline 2 & 0.816 & 0.213 & 10.743 & 0.858 & 0.189 & 20.801 & 0.840 & 0.200 & 15.839 \\
\hline 3 & 0.848 & 0.199 & 4.929 & 0.877 & 0.180 & 3.712 & 0.889 & 0.171 & 10.505 \\
\hline 4 & 0.874 & 0.186 & 4.740 & 0.891 & 0.174 & 3.022 & 0.908 & 0.161 & 4.863 \\
\hline 5 & 0.914 & 0.158 & 10.428 & 0.912 & 0.161 & 5,401 & 0.930 & 0.144 & 7.183 \\
\hline 6 & 0.937 & 0.140 & 8.024 & 0.935 & 0.142 & 7.768 & 0.933 & 0.144 & 0.993 \\
\hline 7 & 0.947 & 0.130 & 4.017 & 0.944 & 0134 & 3.417 & 0.937 & 0.142 & 1.349 \\
\hline 8 & 0.954 & 0.125 & 3.109 & 0.952 & 0.128 & 3.400 & 0.949 & 0.132 & 4.781 \\
\hline
\end{tabular}

${ }^{*} \mathrm{r}$ is the regression coefficient. $s$ is the standard dexiation. $\mathrm{F}_{\mathrm{s}}$ is the sequential $\mathrm{F}$ value. Fs $=\left(r_{2}^{2}-r_{1}^{2}\right) \cdot\left(n-k_{2}-1\right):\left(k_{2}-k_{1}\right) \cdot\left(1-r_{2}^{2}\right)$ where $k$ is the number of terms ( $k_{1}<k_{2}$ ) and $n$ is the number of compounds. 
as the number of terms increases. While all three series of QSAR equations perform at the similar level of confidence and reach the regression coefficient over 0.9 with five terms. the $R S$-equations converge more rapidly. The outstanding convergence of the $R S$-equations is indicated by the $\mathrm{F}_{\mathrm{s}}$ value. which compares two successive regression models. The large $F_{s}$ value strongly justifies the addition of the new term. While the $F_{s}$ values in Table 2 justify the sixth and the seventh terms of $R$ - and $S$-equations, they manifest no requirement for those terms beyond the fifth of the $R S$ equations. Among the five term QSAR equations the RSequation best fits the inhibitory data as indicated by the smallest standard deviation.

In terms of the normalized descriptors. the five term QSAR equations are as follows.

$$
\begin{aligned}
& \mathrm{pIC}_{50}=2.961 \mathrm{TASA}-0.642 \mathrm{~V}_{\mathrm{NCOS}}{ }^{2}+0.428 \mu_{\mathrm{x}}^{2} \\
& +2.108 \mathrm{TPSA}^{2}-1.700 \mathrm{DPSA}_{2}^{2} \quad \text { (R-Equation) } \\
& \mathrm{pIC}_{50}=0.603 \mathrm{Alog} \mathrm{P}-0.573 \mathrm{~V}_{\mathrm{NCOS}}{ }^{2}+0.276 \mu \\
& +0.453 \alpha_{100}^{2}-0.276 \mathrm{PPSA}_{3} \\
& \mathrm{pIC}_{50}=0.869 \mathrm{TASA}-0.442 \mathrm{~V}_{\mathrm{NCOS}}{ }^{2}-0.274 \mu \\
& -0.252 \mathrm{~S}_{\mathrm{y}}^{2}-0.712 \mathrm{DPSA}_{\mathrm{I}}
\end{aligned}
$$

The predicted $\mathrm{pIC}_{\text {sij }}$ values of are listed in Table 1 for each QSAR equation. AlogP is the logaritlum of the partition coefficient. $\mathrm{V}_{\mathrm{N} \text { cos }}$ is the non-common overlap volume. $\mu$ is the dipole moment. $\alpha_{\text {pol }}$ is the sum of atomic polarizability. $S_{y}$ is the length in the $y$-direction. and the other descriptors are surface areas incorporating atomic charges. TASA and AlogP strongly correlate each other with the correlation coefficient over 0.8 . Both represent the hydrophobicity and positively contribute to the inhibitory activity. The negative coefficient of $\mathrm{V}_{\mathrm{NCOS}}{ }^{2}$ indicates that the molecular shape needs to be similar to that of the reference compound for strong interaction with $\mathrm{AR}$. The above $\mathrm{QSAR}$ equations suggest that the hydrophobic interaction plays important role in tight binding to $\mathrm{AR}$ and the interaction is modulated by atomic charge distribution. The correlation matrix of the descriptors in the $R S$-equation has the absolute value average of 0.225 with the maximum 0.427 . The $R S$-descriptors in the QSAR equation substantially less correlate with each other than those in the $R$-equation (the corresponding values are 0.285 and 0.443 . respectively) and the $S$-equation $(0.266$ and 0.585 . respectively). The correlation matrix is another indicator showing that the $R S$-descriptors yield the QSAR
Table 3. $\mathrm{pIC}$ so values predicted by five tem QSAR Equations

\begin{tabular}{lccc}
\hline QSAR model & AS-3201 & SX-3202 & SX-3030 \\
\hline$R$-Equation & 1.491 & 2.670 & 1.900 \\
$S$-Equation & 1.517 & 1.189 & 1.353 \\
$R S$-Equation & 1.715 & 0.958 & 1.337 \\
Observed activity & 1.824 & 0.721 & 1.347 \\
\hline
\end{tabular}

equation in better qualiț:

We further demonstrate superiority of the RS-equation against its $R$ - and $S$-counterparts by predicting the inhibitory activity of enantiomers. While the racemic mixture SX-3030 has the $\mathrm{AR}$ inhibitory activity $0.045 \mu \mathrm{M}$, the $(S)-(+)-$ enantiomer (SX-3202) and $(R)-(-)$-enantiomer (AS-3201) do 0.19 and $0.015 \mu \mathrm{M}$. respectively: Table 3 presents the predicted activity of each five term QSAR equation. The five term $R$-equation predicts the observed $\mathrm{pIC}_{\text {si }}$ values of the enantioners and the racemate with the standard deviation of 1.452 and the $S$-equation does with the standard deviation of 0.369 . The RS-equation predicts those activity values with the standard deviation of 0.185 .

The $R S$-equation is the most robust and stable QSAR equation. It stands with the largest regression coefficient with relatively small number of terms that intercorrelate less than those of $R$ - and $S$-equations. It closely reproduces the observed activity of either optically pure enantiomers or racemic mixtures. The arithmetic mean $R S$-descriptors are suitable to probe QSAR of the activity data assayed with racemates.

\section{References}

1. Suh. M. E.: Park, S. Y.: Lee. H. J. Bull Rorean Chem. Soc. 2003. 23. 417 .

2. Cho. D. H.: Lee. S. K.: Kim, B. T.: No. K. T. Bull Korean Chem. Soc. 2001. 22. 388.

3. Petrash. T. M. Cell Mol. Life Sci. 2004. 61.737.

4. Altan. V. M. Curv Hed Chem 2003. 10. 1317.

5. Suzen. S.: Buyukbingol. E. Cwm Med Chem 2003, 10, 1329

6. Negoro. T: Murata, M:- Ueda. S: Fujitani. B; Ono, Y: Kuromiya A.: Komiya. M.: Suzuki. K.: Matsumoto. J. I. J. Med. Chent 1998. 11. 4118 .

7. Cerius? version 4.6. Accelrys Inc.. San Diego. U.S.A

8. Rappé. A. K.: Goddard. W. A. J. Phws. Chem. 1991. 95. 3358.

9. Rogers, D.: Hopfinger, A. J. J. Chem. Inf. Comput. Sci. 1994, 34. 854. 